\title{
MODEL EKOSISTEM INOVASI UNIVERSITAS (STUDI KASUS DI BANDUNG TECHNO PARK)
}

\section{UNIVERSITY INNOVATION ECOSYSTEM MODEL (CASE STUDY IN BANDUNG TECHNO PARK)}

\author{
Sahara Syarifatul Choeriyah")1 dan Siska Noviaristanti*) \\ *) Magister Manajemen, Fakultas Ekonomi dan Bisnis, Universitas Telkom \\ Jl. Telekomunikasi Terusan Buah Batu 40257 Bandung, Jawa Barat, Indonesia
}

\begin{abstract}
The establishment of a national innovation system is necessary to encourage innovation and socio-economic development. The most important thing in the innovation system is the collaboration of academic, business, community, and government in the innovation ecosystem. The purpose of this study is to determine the actors involved from each entity in the innovation ecosystem, the relationship between actors, and the impact of the relationship between actors. Through case study research method with the object of research at Bandung Techno Park at Telkom University, this study investigates the mutual relationship between entities. Value network analysis is then used to model the innovation ecosystem. This study uses a qualitative method with data collection through interviews with 14 speakers representing each entity. The research results obtained that not all entities have actors who involved in the innovation ecosystem. Some obstacles such as the quality of research, lack of researchers'ability to see market conditions so that innovative products are considered not following the needs of consumers and industries in Indonesia that dominated by agricultural-based industries becomes a difficulty in commercializing technological innovation through licensing. This research shows that BTP's role as Technology Transfer Officer still has shortcomings to align the results of research from academic with business needs. In addition, government regulation has not fully sided with domestic technological innovations to develop.
\end{abstract}

Keywords: university, innovation ecosystem, value network analysis, qualitative method, techno park

\begin{abstract}
Abstrak: Pembentukan sistem inovasi nasional perlu dilakukan untuk mendorong inovasi dan pembangunan sosial ekonomi. Hal yang paling penting dalam sistem inovasi adalah kolaborasi dari akademisi, bisnis, komunitas, dan pemerintah dalam suatu ekosistem inovasi. Tujuan dari penelitian ini, yaitu mengetahui aktor yang terlibat dari setiap entias dalam ekosistem inovasi, hubungan antar aktor, serta dampak dari hubungan antar aktor. Melalui metode penelitian studi kasus dengan objek penelitian Bandung Techno Park di Universitas Telkom, penelitian ini menginvestigasi hubungan timbal balik antar entitas. Analisis jaringan nilai kemudian digunakan untuk memodelkan ekosistem inovasi. Studi ini menggunakan metode kualitatif dengan teknik pengumpulan data melalui wawancara terhadap 14 narasumber yang merepresentasikan setiap entitas. Hasil penelitian mengungkapkan bahwa belum semua entitas memiliki aktor yang terlibat dalam ekosistem inovasi. Hambatan lain seperti kualitas penelitian, kurangnya kepekaan peneliti untuk melihat kondisi pasar sehingga produk inovasi dianggap belum sesuai dengan kebutuhan konsumen serta industri di Indonesia yang didominasi oleh industri berbasis pertanian menjadi sebuah kesulitan untuk mengomersialisasikan inovasi teknologi melalui jalur lisensi. Studi ini menunjukkan bahwa peran Bandung Techno Park sebagai Technology Transfer Office masih memiliki kekurangan untuk menyelaraskan hasil penelitian dari akademisi dengan kebutuhan bisnis. Selain itu, regulasi dari pemerintah pun belum sepenuhnya berpihak pada inovasi teknologi dalam negeri untuk berkembang.
\end{abstract}

Kata kunci: universitas, ekosistem inovasi, analisis jaringan nilai, metode kualitatif, techno park

\footnotetext{
${ }^{1}$ Alamat Korespondensi:

Email: saharasch@student.telkomuniversity.ac.id
} 


\section{PENDAHULUAN}

World Economic Forum (WEF) menjadikan inovasi sebagai salah satu pilar tolak ukur daya saing suatu negara. Tahun 2018, WEF melaporkan bahwa kapabilitas inovasi di Indonesia masih relatif rendah (Setiawan, 2018). Dalam sidang kabinet paripurna tahun 2019, Presiden Joko Widodo juga mengkritik terkait anggaran belanja penelitian dan pengembangan sebesar Rp24,9 trilun, namun tidak melaporkan hasil yang jelas dan konkret yaitu berupa inovasi. Kapabilitas inovasi yang relatif rendah tersebut berdampak pada pertumbuhan ekonomi yang masih stagnan dan belum sesuai dengan ekspektasi pemerintah. Seperti laju pertumbuhan ekonomi pada kuartal I tahun 2019. Pemerintah berharap pertumbuhan ekonomi dapat mendekati 5,2\%, namun pada kenyataannya, Badan Pusat Statistik (BPS) mencatat bahwa pertumbuhan ekonomi kuartal I tahun 2019 adalah 5,07\% (Basari, 2019).

Noviaristani (2018) menyatakan bahwa innovation intermediary merupakan hal penting dalam sistem inovasi. Selanjutnya, Hoang and Ngoc (2019) berpendapat bahwa untuk mendorong inovasi dan pembangunan sosial ekonomi, sangat penting untuk membentuk sistem inovasi nasional. Adapun hal yang paling penting untuk mengalirkan sistem inovasi adalah kolaborasi antara akademisi, bisnis, komunitas, dan pemerintah, atau sering disebut sebagai kolaborasi ABCG (Academic, Business, Community, Government) (Kusharsanto and Pradita, 2016).

Guerrero and Urbano (2012) dalam Tesis karya (Najah, 2017) menjelaskan bahwa universitas adalah sub sistem dari sistem inovasi nasional yang memegang peranan utama dalam riset berbasis inovasi. Salah satu cara untuk meningkatkan kinerja inovasi universitas dalam kolaborasi ABCG (Academic, Business, Community, Government) adalah dengan meningkatkan koordinasi melalui pendekatan ekosistem inovasi universitas (Najah, 2017). Dari kolaborasi tersebut, kemudian Science and Technology Park (STP) muncul dan berperan untuk memungkinkan akademisi di universitas mengomersilkan hasil penelitian mereka terhadap bisnis/industri (Storey and Tether, 1998) dalam literatur (Şimşek and Yıldırım, 2016). Selain itu, STP juga didefinisikan sebagai sarana negara untuk meningkatkan daya saing inovasi dan perpindahan menuju knowledge based economic (Dhewanto et al.
2014). Hal ini sejalan dengan program pemerintah yang menjadikan STP sebagai salah satu program unggulan dari Presiden Joko Widodo dalam Rencana Pembangunan Jangka Menengah Nasional (RPJMN). Ekosistem inovasi yang subur adalah ekosistem yang memfasilitasi pembentukan jaringan yang efektif dan memiliki jalur yang mulus diantara aktor yang berbeda (Sun et al. 2019). Selain itu, Moore (1996) berpendapat bahwa untuk menghasilkan inovasi yang berkelanjutan, perlu mengetahui hubungan timbal balik yang jelas dan saling menguntungkan dari setiap entitas agar dapat memaksimalkan ekosistem.

Dalam penelitian terdahulu, Chais et al. (2018) membahas terkait transfer teknologi yang berasal dari universitas menuju industri. Namun, penelitian tersebut tidak mengembangkan jaringan ekosistem sehingga tidak banyak entitas yang dibahas, melainkan hanya mempelajari peran dari universitas dan industri. Selain itu, penelitian tersebut pun tidak meneliti hambatan yang terjadi dari interaksi antara universitas dengan industri dalam proses transfer teknologi. Sehingga, tidak jelas diketahui apakah kedua entitas tersebut telah memiliki hubungan timbal balik yang saling menguntungkan atau sebaliknya.

Kemudian, Halibas et al. (2017) dalam penelitiannya membahas terkait model inovasi penta helix yang terdiri dari lima entitas yaitu akademisi, pemerintah, bisnis, komunitas, dan pengusaha sosial. Akan tetapi, penelitian tersebut hanya membahas inovasi dari perspektif pendidikan tinggi (higher education) serta tidak menganalisis hubungan antar entitas secara lebih rinci, sehingga belum diketahui apakah telah tercipta hubungan yang saling menguntungkan antar entitas atau belum. Lebih lanjut lagi, Alibekova et al. (2019) mengusulkan untuk mengembangkan ekosistem komersialisasi teknologi berbasis universitas dengan memerhatikan beberapa hal penting seperti sumber daya manusia, pembiayaan, sistem manajemen kekayaan intelektual, dan infrastruktur perantara.

Penelitian ini memperluas studi yang sudah ada dengan mengembangkan ekosistem komersialisasi inovasi teknologi berbasis universitas dengan menggunakan tools untuk memodelkan ekosistem inovasi universitas guna mengetahui apakah setiap entitas yang terlibat dalam ekosistem telah memiliki hubungan timbal balik yang saling menguntungkan dalam proses komersialisasi produk inovasi tersebut. 
Objek studi penelitian ini adalah Bandung Techno Park (BTP). Pendirian BTP merupakan wujud mimpi dari sivitas akademika Universitas Telkom untuk berkontribusi dalam pengembangan ekonomi Indonesia melalui pertumbuhan ekonomi di kawasan Bandung Selatan dengan menyinergikan peran dari beberapa entitas seperti akademisi, bisnis, komunitas, dan pemerintah melalui pendekatan ekosistem inovasi. Pada awal berdirinya, BTP dijadikan sebagai role mode untuk program Nawa Cita pembangunan 100 STP oleh Presiden Joko Wiodo karena dinilai berhasil menyelaraskan riset dengan industri (Zubaidah, 2015). Namun, setelah dilakukan penelitian dan evaluasi tahun 2019, Kementerian Riset, Teknologi dan Perguruan Tinggi melaporkan bahwa kinerja BTP kalah dibanding dengan Solo Techno Park dan Cimahi Techno Park (Harususilo, 2019). Setelah melakukan wawancara dengan Bapak Dana Sulistiyo Kusumo, Ph.D selaku direktur BTP pada tahun 2019, diperoleh informasi bahwa belum diketahui hubungan timbal balik yang jelas antar entitas dalam ekosistem inovasi. Adapun beberapa entitas yang diteliti dalam studi ini yaitu akademisi, bisnis, pemerintah, komunitas, media, dan lembaga keuangan.

Kemudian, terdapat beberapa tools untuk memodelkan ekosistem inovasi telah dilakukan sebelumnya seperti dalam analisis jaringan nilai oleh Allee (2008), Business Ecosystem and Modelling (BEAM) oleh Tian et al. (2008) serta Methodology of Business Ecosystem Network Analysis (MOBENA) oleh Battistella et al. (2013). Sementara tools yang digunakan untuk pemodelan ekosistem dalam penelitian ini adalah analisis jaringan nilai (value network analysis). Analisis jaringan nilai sendiri menawarkan cara untuk memodelkan, menganalisis, serta mengubah aset berwujud dan tidak berwujud menjadi aset lain dalam bentuk nilai yang dapat dinegosiasikan (Allee, 2008).

Analisis jaringan nilai digunakan untuk memodelkan ekosistem inovasi agar bisa mencapai tujuan dari penelitian ini yaitu mengetahui aktor dari setiap entitas yang terlibat dalam ekosistem inovasi, mengetahui hubungan antar aktor baik yang bersifat tangible maupun intangible, serta dampak yang ditimbulkan dari hubungan antar aktor dalam ekosistem inovasi universitas di BTP.

\section{METODE PENELITIAN}

Penelitian ini berlangsung selama 12 bulan. Dimulai dari bulan September 2019 hingga Agustus 2020. Adapun metode yang digunakan dalam penelitian ini adalah metode penelitian kualitatif dengan teknik pengumpulan data melalui wawancara, dimana seluruh kegiatan wawancara dilakukan di Bandung.

Sumber data yang digunakan dalam penelitian ini adalah data primer dan sekunder. Data primer dikumpulkan melalui wawancara dengan narasumber dari BTP untuk memperoleh data awal terkait fenomena yang sedang terjadi. Kemudian, peneliti melakukan wawancara lanjutan terhadap 14 narasumber yang merepresentasikan setiap entitas dalam ekosistem inovasi yaitu akademisi, bisnis, pemerintah, lembaga keuangan, media dan komunitas. Daftar narasumber dalam penelitian ini pada Tabel 1 .

Tabel 1. Daftar Narasumber

\begin{tabular}{|c|c|}
\hline Nama & Jabatan \& Institusi \\
\hline $\begin{array}{l}\text { Bapak Dana } \\
\text { Sulistiyo K, Ph.D. }\end{array}$ & $\begin{array}{l}\text { Direktur Bandung Techno Park } \\
(2018-2019)\end{array}$ \\
\hline $\begin{array}{l}\text { Prof. Dr. Maman } \\
\text { Abdurrohamn, M.T. }\end{array}$ & $\begin{array}{l}\text { Direktur Bandung Techno Park } \\
\text { (2019-sekarang) }\end{array}$ \\
\hline $\begin{array}{l}\text { Ibu Indah } \\
\text { Purnomosari }\end{array}$ & $\begin{array}{l}\text { Manager Pemasaran, Bandung } \\
\text { Techno Park. }\end{array}$ \\
\hline Bapak Eko Rahayu & $\begin{array}{l}\text { Assistant Manager Inovasi dan } \\
\text { Inkubasi, Bandung Techno Park }\end{array}$ \\
\hline Bapak Aan Priyatna & $\begin{array}{l}\text { Principle Expert IT, Telkom } \\
\text { Corporate University }\end{array}$ \\
\hline Bapak Oki & $\begin{array}{l}\text { Coordinator of Faculty Member, } \\
\text { Telkom Corporate University }\end{array}$ \\
\hline Bapak Ihsan & $\begin{array}{l}\text { Founder Startup SISCA (Sistem } \\
\text { Pencatatan Asset) (Startup binaan } \\
\text { BTP) }\end{array}$ \\
\hline $\begin{array}{l}\text { Bapak Angga } \\
\text { Rusdinar, M.T.,Ph.D }\end{array}$ & $\begin{array}{l}\text { Direktur Penelitian dan Pengabdian } \\
\text { Masyarakat, Universitas Telkom }\end{array}$ \\
\hline $\begin{array}{l}\text { Bapak Kiki Sudiana, } \\
\text { S.T., M.M. }\end{array}$ & $\begin{array}{l}\text { Direktur Sumber Daya Manusia, } \\
\text { Universitas Telkom }\end{array}$ \\
\hline Bapak Jonathan & $\begin{array}{l}\text { Manager Incubation Management, } \\
\text { Indigo }\end{array}$ \\
\hline $\begin{array}{l}\text { Ibu Dyas } \\
\text { Nurrahmawati }\end{array}$ & $\begin{array}{l}\text { OFF } 2 \text { Incubation Assessment, } \\
\text { Indigo }\end{array}$ \\
\hline Bapak Budi & $\begin{array}{l}\text { Staff Bidang Aplikasi dan } \\
\text { Informatika, Dinas Komunikasi } \\
\text { dan Informatika Kabupaten } \\
\text { Bandung }\end{array}$ \\
\hline Bapak Opick & $\begin{array}{l}\text { Assistant Manager Product Service } \\
\text { Provider, Radio K-Lite 107.1 FM. }\end{array}$ \\
\hline $\begin{array}{l}\text { Bapak Awan } \\
\text { Rimbawan }\end{array}$ & $\begin{array}{l}\text { Anggota komunitas TDA (Tangan } \\
\text { di Atas) }\end{array}$ \\
\hline
\end{tabular}


Kemudian, sumber data sekunder dalam penelitian ini termasuk tesis serta artikel dari jurnal ilmiah yang memberikan informasi awal untuk melakukan penelitian, serta informasi dari media online yang berisi fakta dan data untuk memperkuat alasan penelitian dilakukan. Selain itu, pengumpulan data sekunder seperti dokumen perjanjian kerja sama dan artikel dari jurnal ilmiah juga dilakukan untuk memperkuat hasil penelitian. Gambar 1 berikut menunjukkan tahapan yang dilakukan selama proses penelitian.
Pengumpulan data awal dilakukan melalui wawancara untuk mengetahui fenomena yang sedang terjadi. Kemudian, peneliti mengidentifikasi permasalahan yang terjadi dari fenomena tersebut. Kajian pustaka juga dilakukan untuk menentukan kesenjangan dan posisi penelitian saat ini. Berdasarkan kajian pustaka tersebut, kemudian peneliti membentuk kerangka pemikiran untuk memetakan garis besar alur logika dari penelitian dalam bentuk gambar. Kemudian, peneliti membuat sebuah rancangan penelitian. Selanjutnya, peneliti melakukan pengumpulan data melalui wawancara guna menjawab pertanyaan penelitian.

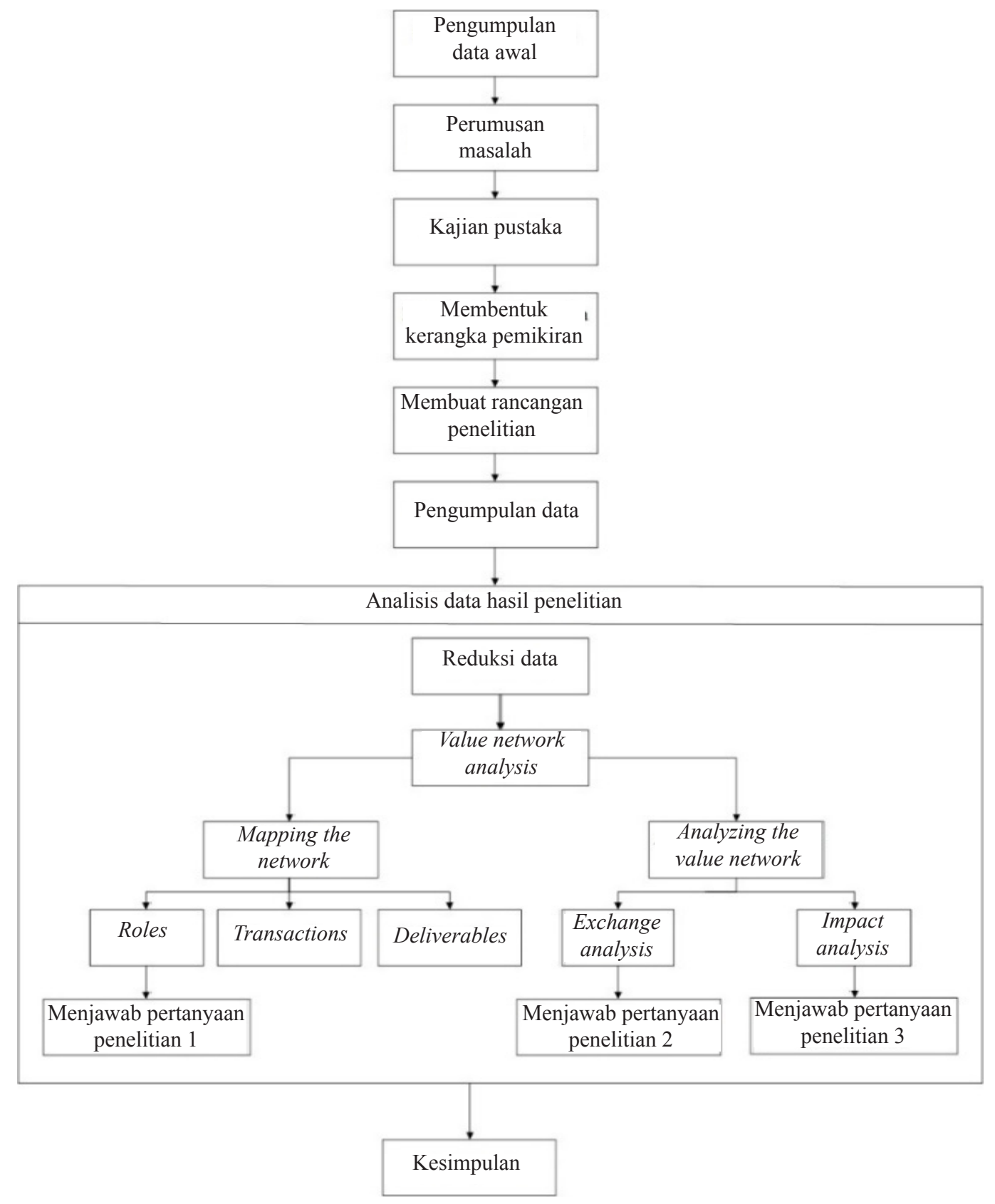

Gambar 1. Tahapan Penelitian 
Menurut Indrawati (2015), metode penelitian kualitatif adalah metode penelitian yang melibatkan analisis berupa deskripsi dan data tersebut tidak dapat secara langsung dikuantifikasi. Penguantifikasian data pada metode ini dilakukan dengan pemberian kode atau kategori. Pengkodean data dilakukan setelah peneliti menyelesaikan wawancara dengan narasumber yang merepresentasikan setiap entitas, yaitu akademisi, bisnis, pemerintah, lembaga keuangan, media, dan komunitas. Hasil dari wawancara tersebut kemudian direduksi dengan menggunakan tipe pengkodean data menurut Charmaz (2016) untuk merangkum, memilih hal-hal yang pokok, serta memfokuskan pada halhal yang penting. Berikut tahapan pengkodean data menurut (Charmaz, 2016).

\section{Initial line-by-line}

Pada tahap ini semua baris data diberi kode. Pemberian kode ini dilakukan perbaris untuk membentuk suatu ide konsep. Tabel 2 berikut merupakan contoh pemberian kode untuk data hasil wawancara yang diperoleh dari lapangan.

\section{Selective Coding}

Pemberian kode perbaris yang dilakukan peneliti menghasilkan 87 kode. Selanjutnya peneliti menyeleksi setiap kode yang paling sesuai dan dibutuhkan untuk menjawab pertanyaan penelitian. Tabel 2 berikut merupakan contoh dari selective coding.

\section{Focused Coding}

Dari kode-kode yang sudah diseleksi, selanjutnya peneliti mengkategorikan kode-kode tersebut agar lebih fokus dan membentuk focused coding untuk kemudian diseleksi kembal menjadi tema besar. Tabel 3 berikut adalah contoh bagaimanafocused coding yang dilakukan dalam penelitian ini. Setelah pengkodean data dilakukan kemudian peneliti melakukan analisis data selanjutnya yaitu analisis jaringan nilai (value network analysis). Analisis tersebut dilakukan berdasarkan data hasil wawancara yang telah direduksi. Terdapat beberapa tahapan dalam analisis jaringan nilai. Pertama, peneliti melakukan pemetaan jaringan dengan salah satu elemen metode pemetaan yaitu peran (roles) untuk menjawab pertanyaan penelitian pertama yaitu mengetahui siapa saja aktor dari setiap entitas dalam ekosistem inovasi di BTP. Adapun peran yang dilakukan oleh aktor dalam jaringan ekosistem inovasi yaitu akademisi, bisnis, pemerintah, lembaga keuangan, media, dan komunitas. Kedua, peneliti melakukan pemetaan jaringan dengan dua elemen pemetaan selanjutnya yaitu transaksi (transaction) dan hasil kerja (deliverables) untuk mengidentifikasi aset berwujud dan tidak berwujud yang mengalir dalam jaringan ekosistem. Ketiga, peneliti melakukan analisis pertukaran nilai (exchange analysis) untuk menilai keseluruhan pola pertukaran nilai dalam jaringan, Tahap ini menghasilkan informasi apakah hubungan antar aktor dalam jaringan ekosistem memiliki hubungan timbal balik yang baik atau terdapat hambatan dalam hubungan tersebut serta menjawab pertanyaan penelitian kedua yaitu bagaimana hubungan timbal balik antar aktor dalam ekosistem inovasi di BTP. Keempat, peneliti melakukan analisis dampak (impact analysis) untuk menganalisis manfaat, biaya/risiko dari input nilai yang diterima oleh setiap peran dalam jaringan ekosistem. Tahap ini memberikan informasi untuk menjawab pertanyaan penelitian ketiga terkait dampak berupa manfaat dan biaya/risiko dari hubungan antar aktor dalam ekosistem inovasi di BTP.

Tabel 1. Contoh initial line-by-line

\begin{tabular}{ll}
\hline Hasil Wawancara & Kode \\
\hline Akademisi itu mereka & 1. Akademisi berperan \\
berperan dalam riset dasar & melakukan riset dasar \\
terapan dan pengembangan & terapan. \\
sementara Bandung & 2. Bandung techno \\
techno park berperan & park berperan untuk \\
dihilirisasi, yaitu dari & menghilirisasi hasil riset \\
riset-riset pengembangan & dari akademisi. \\
nanti dikomersialisasikan & \\
dengan market. & \\
\hline
\end{tabular}

Tabel 2. Selective Coding

\begin{tabular}{ll}
\hline No & Daftar Kode \\
\hline 1 & Akademisi memberikan laporan hasil penelitian \\
2 & Akademisi berperan melakukan riset dasar terapan \\
3 & Bandung techno park membawa penelitian dari \\
& kampus untuk dikomersialisasikan \\
\hline
\end{tabular}

Tabel 3. Focused Coding

\begin{tabular}{llc}
\hline Tema & Focused Coding & Kode \\
\hline Hubungan & Hubungan & 1. Akademisi \\
antar aktor & antara akademisi & memberikan laporan \\
dalam & dengan Bandung & hasil penelitian \\
ekosistem & techno park & 2. Akademisi berperan \\
inovasi di & dalam ekosistem & dalam riset dasar \\
Bandung & inovasi & terapan \\
techno & & 3. Bandung techno park \\
park & & membawa penelitian \\
& & dari kampus untuk \\
& & dikomersiali-sasikan \\
\hline
\end{tabular}


Kerangka pemikiran dalam penelitian ini diadopsi dari penelitian Zhao dan Zheng (2014) dalam literatur (Su et al. 2018) yang menjelaskan sebuah framework yaitu core-peripheral framework, dimana framework tersebut oleh sebagian peneliti disepakati bahwa ekosistem inovasi diciptakan di sekitar simpul pusat yang menyatukan para pemain kunci. Gambar 2 berikut merupakan kerangka pemikiran dari model ekosistem inovasi universitas, dimana BTP berperan sebagai simpul pusat yang menyatukan para pemain kunci dalam ekosistem inovasi yaitu akademisi, bisnis, pemerintah, lembaga keuangan, media, dan komunitas.

\section{HASIL}

\section{Aktor yang Terlibat dalam Ekosistem Inovasi di BTP}

\section{Akademisi}

Aktor yang memainkan peran sebagai akademisi adalah Universitas Telkom yang merupakan salah satu universitas swasta terkemuka di Bandung, Jawa Barat dan berada dalam naungan Yayasan Pendidikan Telkom. Menurut pernyataan Bapak Eko Rahayu sebagai Assistant Manager Inovasi dan Inkubasi Bandung Techno Park mengungkapkan bahwa saat ini Bandung Techno Park berada di bawah koordinasi Universitas Telkom. Maka menjadi salah satu tugas
Bandung Techno Park untuk fokus mendorong inovasi dari Universitas Telkom.

\section{Bisnis}

Aktor yang memainkan peran sebagai bisnis dalam ekosistem inovasi di BTP adalah PT. Telkom Indonesia (Telkom). Telkom merupakan perusahaan utama yang membawahi Yayasan Pendidikan Telkom. Dalam bekerja sama dengan BTP, Telkom menunjuk Telkom Corporate University yang merupakan salah satu bagian pengembangan talent dari perusahaan Telkom untuk menjadi salah satu unit gate agar terhubung ke seluruh institusi pendidikan termasuk Universitas Telkom. Oleh Rektor Universitas Telkom, BTP ditunjuk sebagai unit gate untuk kerja sama dengan Telkom Corporate University. Selanjutnya terdapat aktor lain dari entitas bisnis yang terlibat dalam ekosistem inovasi di BTP yaitu Indigo. Indigo sendiri merupakan inkubator yang masih berada di dalam Telkom Group.

Pemerintah

Terdapat tiga aktor yang memainkan peran sebagai pemerintah dalam ekosistem inovasi di BTP antara lain Kementerian Perindustrian, Kementerian Riset, Teknologi dan Perguruan Tinggi serta Pemerintah Daerah Kabupaten Bandung yang diwakilkan oleh salah satu dinasnya yaitu Dinas Komunikasi dan Informatika Kabupaten Bandung.

Komunitas

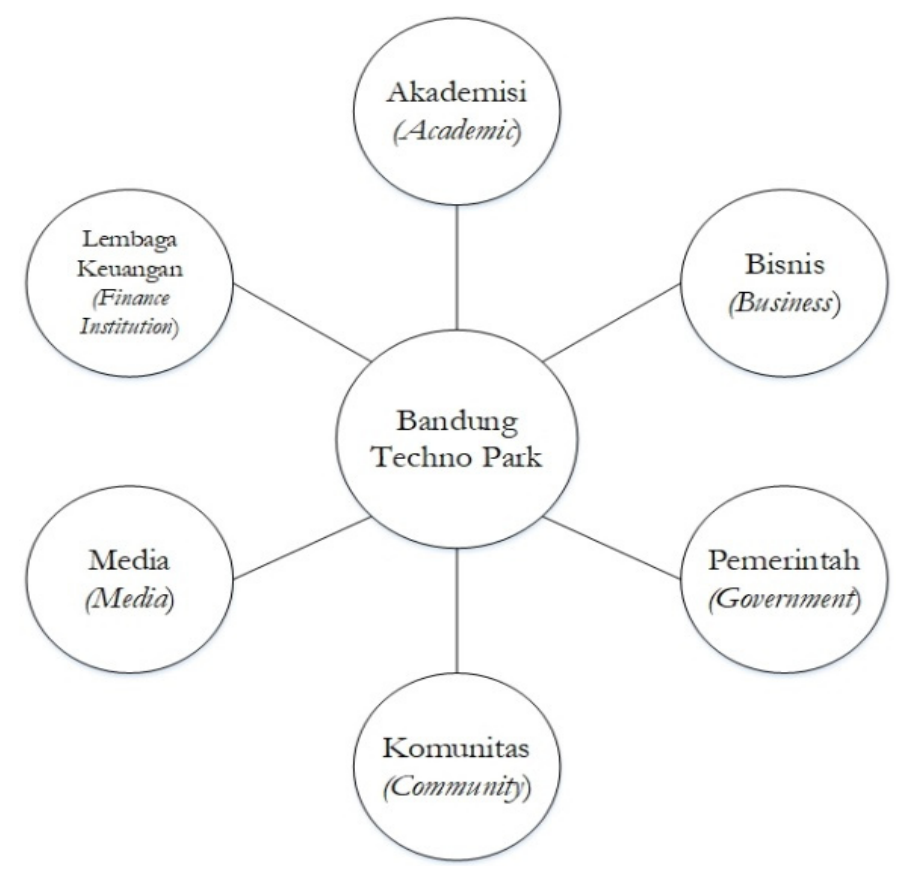

Gambar 2. Kerangka pemikiran 
S Halibas et al. (2017) menjelaskan bahwa kegiatan inovasi tidak terbatas pada pengembangan proyek inovatif, komersialisasi hasil penelitian, paten, dan lisensi. Namun, harus memberikan solusi yang efektif untuk mengatasi masalah sosial. Oleh sebab itu, komunitas perlu dilibatkan secara aktif untuk tujuan sosial dalam agenda penelitian universitas (S Halibas et al. 2017). Sementara berdasarkan hasil wawancara dengan bapak Eko Rahayu selaku Assistant Manager Inovasi dan Inkubasi Bisnis BTP, diperoleh informasi bahwa belum terdapat aktor yang memainkan peran sebagai komunitas dalam ekosistem inovasi di BTP. Saat ini, pihak BTP hanya menyediakan layanan sewa tempat saja untuk komunitas berkumpul dengan sesama anggota mereka. Belum ada program yang melibatkan komunitas untuk berkolaborasi dalam menciptakan inovasi dengan entitas lainnya seperti akademisi, bisnis, pemerintah, dan lembaga keuangan dalam ekosistem inovasi.

\section{Lembaga Keuangan}

Sebuah literatur menjelaskan bahwa yang termasuk kategori lembaga keuangan yaitu business angels, pemodal ventura (venture capitalist), dan crowdfunding (Colombo and Martinu, 2017; Block et al. 2018; Colombo et al. 2019; Cicchiello, 2019). Sementara, berdasarkan hasil wawancara dengan pengelola BTP, belum ditemukan aktor yang termasuk ke dalam kategori lembaga keuangan.

\section{Media}

Media berperan sebagai pendukung publikasi untuk promosi dan membuat brand image (Yunas, 2019). Dalam proses difusi atau penyebaran inovasi, media menjadi salah satu mekanisme yang dapat membantu proses difusi teknologi dikarenakan media dapat menyebarluaskan gagasan kepada lebih banyak orang dalam waktu singkat (Chais et al. 2018). Akan tetapi, berdasarkan hasil wawancara dengan ibu Indah Purnomowati S.T selaku Manager Pemasaran di BTP, diperoleh informasi bahwa belum terdapat aktor yang memainkan peran sebagai media dalam ekosistem inovasi. Hal ini berarti BTP belum menjalin kerja sama dengan media-media besar seperti CNN, Kumparan, Kompas, dan lain sebagainya.

Hasil penelitian lain menunjukkan bahwa penggunaan media sosial dapat meningkatkan kinerja komersialisasi serta memelihara hubungan dengan mitra kerja sama
(Maghsoudi et al. 2019). Dalam hal ini, BTP telah menggunakan media sosial yaitu Instagram untuk memperkenalkan produk inovasi dan kegiatan mereka kepada masyarakat.

\section{Hubungan antar Aktor dalam Ekosistem Inovasi di BTP}

Gambar 3 berikut menunjukkan jaringan nilai (value network) untuk ekosistem inovasi di BTP. Adapun panah dengan label menunjukkan semua transaksi atau aktivitas (transcations) penting suatu hasil kerja (deliverables) yang disampaikan dari satu peran ke peran lain. Hasil kerja (deliverables) tersebut dapat berupa aset berwujud (tangible) maupun aset tidak berwujud (intangible) dalam hubungan antar aktor.

Hubungan antara Universitas Telkom dengan BTP dalam Ekosistem Inovasi

Universitas Telkom sebagai aktor dari akademisi menjadi sumber ide untuk melakukan penelitian dalam ekosistem inovasi guna memberikan solusi bagi permasalahan yang terjadi pada bisnis dengan temuan-temuan baru. Tentunya hal tersebut sesuai dengan teori yang menerangkan bahwa akademisi berperan sebagai konseptor dalam menciptakan inovasi. Dalam hal ini akademisi merupakan sumber pengetahuan dengan konsep, teori-teori terbaru dan relevan dengan kondisi saat ini (Yunas, 2019). Menurut bapak Angga Rusdinar, Ph.D selaku Direktur Penelitian dan Pengabdian Masyarakat (PPM) di Universitas Telkom, menjelaskan bahwa hasil penelitian dosen maupun mahasiswa di Universitas Telkom tidak sampai ke arah komersialisasi, maka laporan hasil penelitian tersebut diberikan kepada BTP untuk kemudian dilihat hasil penelitian yang berpotensi untuk dikomersialisasikan.

Selanjutnya, bapak Kiki Sudiana, ST, MM, GPHR selaku Direktur Sumber Daya Manusia di Universitas Telkom, mengungkapkan bahwa BTP berperan sebagai Technology Transfer Office (TTO) untuk menghilirisasi hasil riset dari akademisi menuju bisnis dengan cara mengomersialisasikan inovasi produk teknologi yang berasal dari hasil riset tersebut. Hal ini sejalan dengan penelitian terdahulu yang dilakukan oleh Rasmussen et al. (2008) dalam literatur Secundo et al. (2017) bahwa selain menjalankan tujuan tradisional seperti pendidikan dan penelitian, mayoritas universitas di dunia barat telah memasukkan technology transfer ke dalam tujuan mereka dengan membentuk Technology Transfer Office (TTO). 
Technology Transfer Office (TTO) memainkan peran penting dalam siklus hidup inovasi, memanfaatkan keterampilan dan peran universitas dalam masyarakat, memungkinkan kerja sama antara akademisi, pusat teknologi dan asosiasi bisnis, berkontribusi pada pendaftaran paten serta transfer pengetahuan dan teknologi (Mascarenhas et al. 2019). Selanjutnya, Lundquist (2013), Swamidass and Vulasa (2013) dalam literatur Secundo et al. (2017) mendefinisikan transfer teknologi sebagai suatu proses dimana sains, pengetahuan, atau kemampuan dipindahkan dari suatu entitas ke entitas lain untuk tujuan pengembangan atau komersialisasi lebih lanjut.

Terdapat tiga jalur untuk hilirisasi riset. Pertama, melalui skema kerja sama lisensi dengan bisnis/ industri. Kedua, melalui star-up binaan BTP. Ketiga, menjual produk teknologi dari hasil penelitian secara langsung kepada bisnis. Adapun hilirisasi riset yang terjadi saat ini adalah dengan menjual produk teknologi dari hasil penelitian secara langsung kepada bisnis melalui program Solve IT. Melalui program tersebut, bisnis menceritakan permasalahan mereka, kemudian akademisi diminta untuk melakukan penelitian yang bisa menjadi solusi teknologi untuk permasalahan tersebut. Selain itu, bisnis pun bisa menggunakan produk teknologi dari start-up binaan BTP, bila sesuai dengan permasalahan mereka. Sementara hilirisasi riset melalui skema kerja sama lisensi dengan bisnis dan melalui start-up binaan BTP belum terjadi. Bahkan sebagian besar hasil penelitian dari dosen maupun mahasiswa di Universitas Telkom hanya berakhir pada publikasi jurnal saja, yang berarti hasil riset tersebut tidak sampai pada proses komersialisasi serta tidak dirasakan kebermanfaatannya oleh masyarakat.

Bapak Kiki Sudiana, S.T., M.M., GPHR selaku Direktur Sumber Daya Manusia di Universitas Telkom berpendapat bahwa kualitas penelitian, pola pikir peneliti untuk mengomersialisasikan hasil penelitian, serta kemampuan peneliti yang kurang peka untuk melihat kebutuhan pasar merupakan hambatan dalam proses hilirisasi riset. Selain itu, salah founder dari start up binaan BTP yaitu Ihsan, mengungkapkan bahwa terkadang hasil penelitian dari akademisi terlalu rumit dan tidak sesuai dengan apa yang dibutuhkan di lapangan. Sehingga, sebagian besar ide awal start-up pun bukan berasal dari penelitian dosen atau mahasiswa di Universitas Telkom.

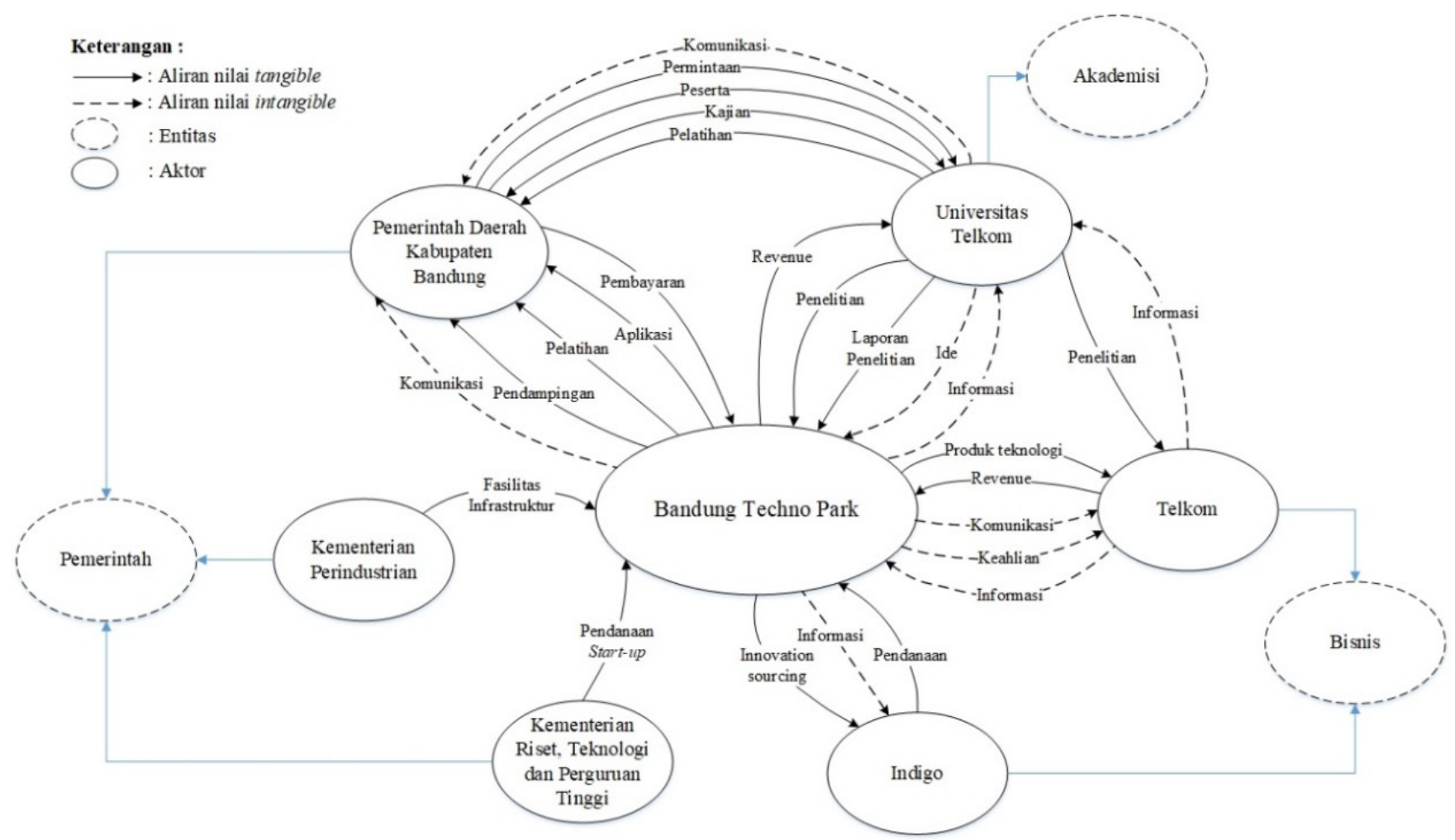

Gambar 3. Jaringan Nilai (Value Network) Ekosistem Inovasi di BTP 
Keefektifan pemindahan teknologi dari hasil penelitian akademisi menuju bisnis, salah satunya ditentukan oleh kompetensi para peneliti. Maka, menjadi sebuah keharusan bagi BTP yang berperan sebagai TTO untuk mengatasi permasalahan tersebut dengan memberikan pelatihan atau pendidikan untuk dosen atau pun mahasiswa dari akademisi mengenai hal spesifik dalam proses bisnis, peran bisnis, serta bagaimana berinteraksi dengan bisnis (Siegel and Phan, 2015). Kemudian, sangatlah penting bagi Universitas Telkom untuk membekali fakultas dan mahasiswa dengan pola pikir kewirausahaan untuk memahami bisnis dengan menghubungkan bakat dan kebutuhan industri. Korelasi antara industri dengan penelitian dari akademisi dapat menghasilkan pengetahuan dan menciptakan bisnis baru (Hassan, 2020).

Selain itu, Universitas Telkom perlu menjadikan entrepreneurial university sebagai bagian dari rencana strategis mereka. Entrepreneurial university dapat mendorong budaya inovasi dan kewirausahaan, membantu proses pemindahan teknologi, memperhatikan pasar, mengembangkan penelitian berbasis teknologi, membantumenghasilkan perusahaan baru yang berdampak pada teknologi (Chais et al. 2018) dengan tidak hanya menyediakan laboratorium untuk fakultas dan mahasiswa saja, tetapi mentransfer ide dari mahasiswa ke ruang inkubator untuk memasarkan penemuan mereka (Wolf, 2017).

Bapak Kiki Sudiana, S.T., M.M., GPHR selaku Direktur Sumber Daya Manusia di Universitas Telkom menjelaskan bahwa terdapat keuntungan yang bisa didapatkan bila hilirisasi riset melalui skema kerja sama lisensi dengan bisnis terjadi. Melalui skema kerja sama tersebut, peneliti bisa mendapatkan royalti dari produk teknologi yang dipakai oleh industri. Namun, selain kualitas penelitian, pola pikir peneliti, serta kurangnya kepekaan peneliti terhadap kebutuhan pasar, industri di Indonesia yang didominasi oleh industri berbasis pertanian maupun pertambangan menjadi sebuah kesulitan untuk melisensikan inovasi produk teknologi melalui kerja sama lisensi dengan bisnis.

Hubungan antara Telkom dengan BTP dalam Ekosistem Inovasi

Selain untuk mengomersialisasikan hasil penelitian dari Universitas Telkom, BTP menjadi salah satu mitra yang memberikan sumber daya untuk mendukung aktivitas di Telkom sebagai aktor dari entitas bisnis seperti menghadirkan programmer untuk membenahi sistem internal serta mencari sumber daya dari Universitas Telkom untuk membantu mengembangkan materi ajar. Kemudian, selain berkolaborasi untuk memberikan pelayanan terhadap Telkom Group, BTP dengan Telkom juga berkolaborasi untuk memberikan pelayanan terhadap BUMN lain, Kementerian, lembaga negara, bahkan swasta yang menjadi client Telkom.

Ketika ada permintaan dari bisnis, BTP menginformasikan hal tersebut kepada peneliti di akademisi sebagai salah satu sumber daya yang dalam ekosisteminovasiuntuk kemudianmelakukan penelitian guna memenuhi permintaan tersebut. Akan tetapi, pengembangan produk teknologi oleh BTP yang dinilai masih berorientasi pada produk (customer oriented) menjadi salah satu hambatan dalam hubungan antara BTP dengan bisnis. Sebab, dalam mengembangkan sebuah produk teknologi harus bisa bermanfaat dan disesuaikan dengan kebutuhan konsumen (customer oriented). Dalam penelitian sebelumnya yang dilakukan oleh (Maludin et al. 2019), mengungkapkan bahwa antar mediator dan akselerator harus memiliki kemampuan komunikasi yang luar biasa. Sebab, dalam pemindahan teknologi, proses menjembatani penelitian ke pemanfaatannya adalah proses paling rumit.

Seorang Guru Besar Fakultas Kedokteran Universitas Indonesia pun menjelaskan bahwa Technology Transfer Office (TTO) harus memiliki kemampuan untuk membaca dan menerjemahkan kebutuhan pasar serta bekerja cepat, jeli, dan tidak bosan untuk melihat potensi kebaruan yang dibutuhkan oleh masyarakat. Sehingga, akan mengakselerasi pusat riset untuk segera mewujudkannya melalui sebuah produk (Rassat, 2019). Oleh sebab itu, BTP yang berperan sebagai Technology Transfer Office (TTO) harus terus melatih dan meningkatkan kemampuan para peneliti dari akademisi untuk mengamati kebutuhan bisnis/ industri agar tercapai kesesuaian antara inovasi produk teknologi dengan kebutuhan bisnis/industri (product market fit). Lebih lanjut lagi, Osterwalder et al (2014) menjelaskan bahwa product market fit terjadi ketika suatu produk mampu menjadi pereda kesulitan (pain relievers) dari permasalahan konsumen serta menjadi pencipta keuntungan (gains creators) yang esensial dan dipedulikan oleh konsumen. 
Selanjutnya kecepatan dalam melakukan penelitian relatif lama, sehingga terkadang proses deliver produk teknologi pun menjadi lebih lama. Hal ini tentunya dikarenakan peneliti di BTP yang juga sebagian besar adalah dosen di Universitas Telkom, memilikikewajiban yang tidak hanya berfokus pada penelitian saja, tetapi juga berfokus pada hal lain seperti pengajaran dan pengabdian masyarakat atau dikenal dengan sebutan Tri Dharma dosen, yaitu pengajaran, penelitian, dan pengabdian masyarakat.

Hubungan antara Universitas Telkom dengan Telkom dalam Ekosistem Inovasi

Tidak hanya memiliki hubungan kerja sama dengan BTP, Telkom sebagai aktor dari bisnis juga memiliki hubungan kerja sama dengan Universitas Telkom dalam melakukan penelitian, dimana dosen di Universitas Telkom mengerjakan penelitian yang berhubungan dengan bisnis Telkom. Namun, bila terdapat suatu produk yang harus dikembangkan, maka pengembangan produk tersebut akan dikerjakan oleh BTP.

Hubungan antara Kementerian Perindustrian dengan BTP dalam Ekosistem Inovasi

Dalam ekosistem inovasi, Kementerian Perindustrian memberikan hibah berupa fasilitas infrastruktur kepada BTP seperti gedung serta peralatan lainnya untuk mendukung kegiatan inovasi, dimana nantinya BTP memiliki kewajiban untuk melayani industri yang berkaitan dengan ICT. Sejalan dengan pernyataan Okunji (2016) dalam literatur S Halibas et al. (2017) bahwa pemerintah mendukung universitas melalui pembangunan infrastruktur, pendirian laboratorium pusat teknologi dan science park, pusat pelatihan dan pusat inkubasi, konsultasi layanan, keterampilan dan transfer teknologi, perusahaan spin-off, startup, dan lain-lain.

Hubungan antara Kementerian Riset, Teknologi dan Perguruan Tinggi dengan BTP dalam Ekosistem Inovasi

Sementara itu, Kementerian Riset, Teknologi dan Perguruan Tinggi berperan dalam memberikan pendanaan untuk start-up. Pendanaan tersebut tidak langsung diberikan kepada BTP, melainkan melalui program PPBT (Perusahaan Pemula Berbasis Teknologi). Start-up yang mengikuti program tersebut diberikan daftar inkubator untuk selanjutnya mengikuti program inkubasi di inkubator tersebut. BTP sendiri merupakan salah satu inkubator yang banyak dipilih dalam program tersebut.

Selaras dengan pernyataan (Yunas, 2019) yang menjelaskan bahwa pemerintah berperan sebagai regulator sekaligus kontroler yang memiliki tanggung jawab dalam mengembangkan inovasi, dimana hal tersebut melibatkan beberapa jenis kegiatan seperti perencanaan, pelaksanaan, pemantauan, pengendalian, promosi, alokasi keuangan, perizinan, program, undang-undang, pengembangan dan pengetahuan, kebijakan inovasi publik, serta dukungan untuk jaringan kemitraan publik-swasta.

Namun untuk saat ini, peran pemerintah sebagai regulator masih belum sepenuhnya berpihak pada inovasi teknologi dalam negeri. Sebagaimana diungkapkan oleh Bapak Eko Rahayu selaku Assistant Manager Inovasi dan Inkubasi Bisnis BTP bahwa industri di Indonesia yang didominasi oleh industri berbasis pertanian maupun pertambangan menjadi sebuah kesulitan untuk melisensikan inovasi produk teknologi dalam negeri. Hasil penelitian yang dilakukan oleh Maludin et al. (2019) pun menyatakan bahwa jumlah hak paten produk lokal pun masih terbilang rendah, bila dibandingkan dengan nomor paten luar negeri di Indonesia.

Hubungan antara Pemerintah Daerah Kabupaten Bandung dengan BTP dalam Ekosistem Inovasi

Selanjutnya, hubungan BTP dengan Pemerintah Daerah Kabupaten Bandung yaitu memberikan pendampingan untuk program pemerintah salah satunya program SPBE (Sistem Pemerintah Berbasis Elektronik), serta melakukan pengembangkan aplikasi sekaligus memberikan pelatihan untuk penggunaan aplikasi tersebut. Sebaliknya, Pemerintah Daerah Kabupaten Bandung memberikan pembayaran sebesar pekerjaan yang telah dilakukan oleh BTP.

Hubungan antara Pemerintah Daerah Kabupaten Bandung dengan Universitas Telkom

Hubungan Pemerintah Daerah Kabupaten dengan Universitas Telkom yaitu dalam melakukan penelitian untuk pembuatan kajian serta memberikan program pelatihan seperti pelatihan Word Dasar atau Coding 
Dasar, dimana Pemerintah Daerah Kabupaten Bandung mengirimkan beberapa Aparatur Sipil Negara (ASN) untuk mengikuti program pelatihan tersebut. Akan tetapi terdapat suatu tantangan dalam hubungan tersebut, seperti kesibukan dari peneliti yang terkadang mengakibatkan suatu pekerjaan menjadi terselesaikan melebihi batas waktu yang telah disepakati. Hal tersebut pun selaras dengan penjelasan Okunji (2016) dalam literatur S Halibas et al. (2017) mendukung universitas melalui program pelathan untuk memperoleh dan mentransfer pengetahuan.

Hubungan antara Indigo dengan BTP dalam Ekosistem Inovasi

Selain mendapatkan pendanaan dari Kementerian Riset, Teknologi dan Perguruan Tinggi, BTP mendapatkan pendanaan untuk start-up dari kerja sama dengan Indigo melalui program co-incubation, dimana BTP mengirimkan start-up binaan mereka yang berpotensi untuk disinergikan dengan Telkom Group untuk masuk program inkubasi indigo. Kemudian, BTP dan Indigo bersama-sama melakukan inkubasi untuk start-up tersebut. BTP merupakan salah satu innovation sourcing bagi Indigo dalam mencari start-up yang berpotensi. Sebaliknya, Indigo memberikan pendanaan untuk start-up yang berasal dari BTP tersebut. Meskipun Indigo berperan dalam memberikan pendanaan dalam ekosistem inovasi. Namun, Indigo tidak dikategorikan sebagai aktor dari lembaga keuangan. Sebab, dalam ekosistem inovasi, penyedia sumber daya keuangan seperti business angels, pemodal ventura (venture capitalist), serta crowdfunding yang dikategorikan sebagai lembaga keuangan (Colombo and Martinu, 2017; Block et al. 2018; Colombo et al. 2019; Cicchiello, 2019).

\section{Dampak dari Hubungan antar Aktor dalam Ekosistem Inovasi}

Terdapat 3 transaksi (transaction) dari hubungan antar aktor dalam ekosistem inovasi yang memiliki dampak berupa biaya atau tingkat risiko tinggi apabila melakukan dan atau tidak melakukan aktivitas tersebut. Pertama, aktivitas yang terjadi dari hubungan Telkom dengan BTP dalam memberikan informasi terkait kebutuhan teknologi dari client Telkom. Bila aktivitas ini tidak dilakukan dengan baik, maka akan berdampak pada kesalahpahaman dalam pertukaran informasi yang mengakibatkan ketidaktercapaian output dari produk teknologi serta akan menurunkan tingkat penjualan produk teknologi di BTP. Kedua, aktivitas yang terjadi dari hubungan Universitas Telkom dengan BTP dalam melakukan penelitian untuk solusi permasalahan bisnis. Manfaat dari aktivitas ini adalah meningkatkan akreditasi kampus, memenuhi NTF (Non Tultion $\mathrm{Fee})$ dari Universitas Telkom serta menghasilkan pendapatan untuk dosen dan tim BTP. Oleh karena peneliti di Universitas Telkom tidak hanya berfokus pada penelitian saja, aktivitas ini berdampak pada waktu pengerjaan proyek yang relatif lama, dimana hal tersebut dapat memengaruhi tingkat kepuasan dari bisnis dalam bekerja sama dengan BTP. Ketiga, aktivitas yang terjadi dari hubungan Telkom dengan BTP dalam melakukan pembayaran produk teknologi. Aktivitas ini berisiko mengakibatkan kerugian apabila terjadi tagihan yang tidak terbayarkan dari Telkom terhadap BTP.

\section{Implikasi Manajerial}

Berkenaan dengan implikasi manajerial, hasil penelitian yang diperoleh diharapkan dapat membantu memberikan rekomendasi bagi pihak Bandung Techno Park untuk menambah sumber daya manusia agar dapat menggandeng entitas lain yang belum terlibat dalam ekosistem inovasi. Selanjutnya, Bandung Techno Park diharapkan dapat memberikan pelatihan atau pendidikan untuk dosen atau pun mahasiswa guna mengetahui bagaimana cara berinteraksi dengan bisnis agar produk teknologi yang dikembangkan sesuai dengan kebutuhan bisnis. Selain memberikan rekomendasi bagi Bandung Techno Park, penelitian ini pun diharapkan dapat menjadi masukan bagi Universitas Telkom untuk menyediakan skema insentif, sistem penghargaan, pengembangan profesional dan instruktur TIK untuk memotivasi orang agar terlibat dalam praktik inovasi (Geels, 2002) dimuat dalam artikel yang ditulis oleh artikel (S Halibas et al. 2017).

Penelitian ini diharapkan dapat menjadikan entrepreneurial university sebagai bagian dari rencana strategis guna mendorong budaya inovasi dan kewirausahaan serta melibatkan pihak Bandung Techno Park atau profesional industri untuk merancang kurikulum universitas agar dapat mempertajam serta menyempurnakan pengetahuan, keterampilan, dan keahlian sumber daya manusia (UNCTAD, 2014) dalam artikel (S Halibas et al. 2017). Selanjutnya, penelitian ini pun diharapkan mampu membantu 
munculnya kebijakan baru terkait regulasi yang lebih rinci untuk menumbuhkan dan melindungi produk inovasi pemain lokal dari ancaman pemain asing serta tidak menghambat produk inovasi dalam negeri untuk berkembang.

\section{KESIMPULAN DAN SARAN}

\section{Kesimpulan}

Hasil penelitian mengungkapkan bahwa belum semua entitas memiliki aktor yang terlibat secara aktif dalam ekosistem inovasi di BTP, seperti lembaga keuangan, media, dan komunitas. Kekurangan sumber daya manusia menjadi salah satu faktor belum terlibatnya entitas tersebut. Selain itu, peran BTP sebagai Technology Transfer Office (TTO) dalam jaringan ekosistem inovasi juga dinilai belum maksimal.

Dalam melakukan perannya sebagai Technology Transfer Office (TTO), BTP sendiri bertugas untuk menghilirisasi penelitian dosen di Universitas Telkom yang menjadi aktor dari akademisi menuju bisnis. Terdapat tiga jalur dalam hilirisasi riset yaitu melalui skema kerja sama lisensi dengan bisnis/industri, melalui start-up binaan BTP dan menjual produk inovasi teknologi secara langsung terhadap bisnis/industri. Akan tetapi, hilirisasi riset melalui skema kerja sama lisensi dan melalui start-up belum terjadi. Kualitas penelitian, pola pikir peneliti, serta kemampuan peneliti yang kurang peka untuk melihat kebutuhan pasar menjadi hambatan proses hilirisasi riset tersebut. Selain itu, industri Indonesia yang didominasi oleh industri berbasis pertanian, pertambangan, dan lain sebagainya menjadi sebuah kesulitan untuk mengomersialisasikan inovasi produk teknologi melalui jalur lisensi. Sementara dalam sebuah teori dijelaskan bahwa Technology Transfer Office (TTO) berperan sebagai agen lisensi yang mengoordinasikan interkasi antara universitas, fakultas/penemu, dengan industri untuk melisensikan kekayaan intelektual universitas. Namun di Indonesia sendiri, keberpihakan regulasi yang mengatur lisensi hak paten di bidang inovasi teknologi masih perlu ditinjau ulang, dimana jumlah hak paten produk lokal masih terbilang rendah, bila dibandingkan dengan nomor paten luar negeri di Indonesia (Maludin et al. 2019).
Adapun hilirisasi riset yang terjadi saat ini adalah dengan menjual langsung inovasi produk teknologi melalui program Solve IT serta melalui kerja sama dengan Telkom sebagai aktor dari entitas bisnis untuk memberikan solusi teknologi terhadap perusahaan lain yang menjadi client Telkom. Namun, Telkom sebagai aktor dari bisnis menilai bahwa pengembangan produk teknologi oleh BTP masih memiliki kekurangan karena hasil penelitian dari Universitas Telkom belum berorientasi pada konsumen atau belum sesuai dengan kebutuhan konsumen.

Selain itu, kecepatan dari peneliti dalam melakukan penelitian untuk solusi teknologi bagi permasalahan bisnis yang menjadi client Telkom serta dalam mengerjakan program dengan Pemerintah Daerah Kabupaten Bandung dinilai masih lambat sehingga menyebabkan pekerjaan terselesaikan melebihi batas waktu. Oleh sebab itu, BTP masih memiliki kekurangan dalam menyinergikan Universitas Telkom sebagai aktor dari akademisi dengan Telkom sebagai aktor dari entitas bisnis, serta antara Universitas Telkom dengan Pemerintah Daerah Kabupaten Bandung sebagai salah satu aktor dari entitas pemerintah dalam ekosistem inovasi. Sementara hubungan BTP dengan Indigo sebagai salah satu aktor dari entitas bisnis, sudah berjalan dengan baik. Hubungan BTP dengan dua aktor dari pemerintah yaitu Kementerian Perindustrian dan Kementerian Riset, Teknologi dan Perguruan Tinggi juga berjalan baik

\section{Saran}

Bandung Techno Park sebaiknya mengembangkan produk teknologi yang sesuai dengan kebutuhan konsumen (customeroriented), meningkatkankecepatan dalam mengembangkan produk teknologi, memperluas konten IT sesuai dengan kebutuhan industri 4.0 seperti artificial intelligent, internet of things, big data, dan lain sebagainya,

Studi untuk menganalisis budaya inovasi dan kewirausahaan dalam entrepreneurial university untuk penelitian dimasa depan diperlukan guna mengetahui sejauh mana akademisi di universitas telah menerapkan konsep entrepreneurial university. Selain itu, studi untuk mempelajari regulasi pemerintah terkait inovasi juga dibutuhkan guna mengetahui apakah regulasi tersebut mendorong terciptanya inovasi atau justru menghambat proses inovasi dalam negeri untuk berkembang. 


\section{DAFTAR PUSTAKA}

Alibekova G et al. 2019. Determinants of Technology Commercialization Ecosystem for Universities in Kazakhstan. The Journal of Asian Finance, Economics and Business 6(4): 271-279.

Allee V. 2008. Value network analysis and value conversion of tangible and intangible assets. Journal of Intellectual Capital 9(1): 5-24.

Basari MT. 2019. Data Pertumbuhan Ekonomi Indonesia Kuartal I/2019. https://ekonomi.bisnis.com. [19 Sept 2019].

Battistella C et al. 2013. Methodology of business ecosystems network analysis: A case study in telecom italia future centre. Technological Forecasting and Social Change 80(6): 11941210.

Chais C, Ganzer PP, Olea MP. 2018. Technology transfer between universities and companies. Innovation \& Management Review 15(1): 20-40.

Charmaz K. 2016. Constructing Grounded Theory A Practical Guide Through Qualitative Analysis. London: Sage Publication.

Cicchiello AF. 2019. Building an entrepreneurial ecosystem based on crowdfunding in Europe: the role of public policy. Journal of Entrepreneurship and Public Policy 8(3): 297-318.

Dhewanto W et al. 2014. Manajemen Inovasi - Peluang Sukses Menghadapi Perubahan. Yogyakarta: Andi.

Ganjeh YM., Khani N, Tabriz AA. 2019. Social media usage and commercialization performance: role of networking capability. Journal of Science and Technology Policy Management 10(5): 11741195.

Halibas SA, Sibayan RO, Maata RLR. 2017. The Penta Helix Model of Innovation in Oman: An HEI Perspective. Interdisciplinary Journal of Information, Knowledge, and Management 12: 159-174.

Harususilo YE. 2019. 6 Kota/Kabupaten dengan Sistem Iptek dan Inovasi Terbaik versi Kemenristekdikti. https://edukasi.kompas.com. [24 Nov 2019].

Hassan NA. 2020. University business incubators as a tool for accelerating entrepreneurship: theoretical perspective. Review of Economics and Political Science ahead-of-print(ahead-of-print).

Hoang CC, Ngoc BH. 2019. The relationship between innovation capability and firm's performance in electronic companies, Vietnam. Journal of Asian Finance, Economics and Business 6(3):
295-304.

Indrawati. 2015. Metode Penelitian Manajemen dan Bisnis Konvergensi Teknologi Komunikasi dan Informasi. Bandung: PT. Refika Aditama.

Kusharsanto ZS, Pradita L. 2016. The Important Role of Science and Technology Park towards Indonesia as a Highly Competitive and Innovative Nation. Procedia - Social and Behavioral Sciences 227(2016): 545-552.

Maludin S et al. 2019. Strategic Choice of Technology Transfer In Indonesia. Jurnal Aplikasi Bisnis dan Manajemen 5(1): 163-175.

Mascarenhas C et al. 2019. Analyzing technology transfer offices' influence for entrepreneurial universities in Portugal. Management Decision 57(12): 3473-3491.

Moore J. 1996. The Death of Competition: Leadership and Strategy in the Age of Business Ecosystems. New York: HarperBusiness.

Najah Z. 2017. Model Kelembagaan Ekosistem Inovasi Universitas: Studi Kasus Institut Pertanian Bogor [tesis]. Bogor: Sekolah Pascasarjana, Institut Pertanian Bogor.

Noviaristani S. 2018. The Orchestration Role of Innovation Intermediary: A Case of Corporate Accelerator Program [disertasi]. Glasgow: University of Strathclyde. Available at: British Library EThOS: The orchestration role of innovation intermediary : a case of corporate accelerator programme (bl.uk).

Osterwalder A et al. 2014. Value Proposition Design. Hoboken New Jersey: John Willey \& Sons Inc.

Rassat FS. 2019. Diperlukan Technology Transfer Office agar riset tak sia-sia. https://www. antaranews.com. [12 Mei 2020].

Secundo G et al. 2017. Mobilising intellectual capital to improve European universities' competitiveness: the technology transfer offices' role. Journal of Intellectual Capital 18(3): 607-624.

Setiawan SRD. 2018. Peringkat Daya Saing Indonesia Naik ke Posisi 45. https://ekonomi.kompas.com. [19 Sept 2019].

Siegel DS, Phan PH. 2015. Analyzing The Effectiveness of University Technology Transfer : Implications for Entrepreneurship Education', in University Entrepreneurship and Technology Transfer (Advances in the Study of Entrepreneurship, Innovation and Economic Growth, Vol. 16). Bingley: Emerald Group Publishing Limited, pp. 1-38.

Şimşek K, Yıldırım N. 2016. Constraints to Open 
Innovation in Science and Technology Parks. Procedia - Social and Behavioral Sciences 235: 719-728.

Su YS, Zheng ZX, Chen J. 2018. A multi-platform collaboration innovation ecosystem: the case of China. Management Decision 56(1): 125-142.

Sun SL et al. 2019. Enriching innovation ecosystems: The role of government in a university science park. Global Transitions 1: 104-119.

Tian $\mathrm{CH}$ et al. 2008. BEAM: A framework for business ecosystem analysis and modeling. IBM Systems Journal 47(1): 101-114.
Wolf G. 2017. Entrepreneurial university: a case study at Stony Brook University. Journal of Management Development 36(2): 286-294.

Yunas NS. 2019. Implementasi Konsep Penta Helix Dalam Pengembangan Potensi Desa Melalui Model Lumbung Ekonomi Desa di Provinsi Jawa Timur. Jurnal Inovasi Kebijakan 3(1): 37-46.

Zubaidah N. 2015. Bandung Techno Park Jadi Panutan Pembuatan 100 Pusat Saintek. https://news. okezone.com. [5 Sept 2019]. 